\title{
Cervical radiographic parameters in 1- and 2-level anterior cervical discectomy and fusion
}

\author{
Christopher C. Gillis, MD, ${ }^{1}$ Megan C. Kaszuba, BA, ${ }^{2}$ and Vincent C. Traynelis, MD ${ }^{3}$ \\ 'Division of Neurosurgery, University of Nebraska Medical Center, Omaha, Nebraska; ${ }^{2}$ Rush Medical College, Chicago; and \\ ${ }^{3}$ Department of Neurosurgery, Rush University Medical Center, Chicago, Illinois
}

\begin{abstract}
OBJECTIVE Anterior cervical discectomy and fusion (ACDF) is one of the most commonly performed spine procedures. It can be used to correct cervical kyphotic deformity, which is the most common cervical deformity, and is often performed using lordotic interbody devices. Worsening of the cervical sagittal parameters is associated with decreased health-related quality of life. The study hypothesis is that through the use of machined lordotic allografts in ACDF, segmental and overall cervical lordosis can be maintained or increased, which will have a positive impact on overall cervical sagittal alignment.
\end{abstract}

METHODS Seventy-four cases of 1-level ACDF (ACDF1) and 2-level ACDF (ACDF2) (40 ACDF1 and 34 ACDF2 procedures) were retrospectively reviewed. Upright neutral lateral radiographs were assessed preoperatively and at 6 weeks and 1 year postoperatively. The measured radiographic parameters included focal lordosis, disc height, C2-7 lordosis, C1-7 lordosis, T-1 slope, and C2-7 sagittal vertical axis. Correlation coefficients were calculated to determine the relationships between these radiographic measurements.

RESULTS The mean values were as follows: preoperative focal lordosis was $0.574^{\circ}$, disc height was $4.48 \mathrm{~mm}, \mathrm{C} 2-7$ lordosis was $9.66^{\circ}, \mathrm{C} 1-7$ lordosis was $42.5^{\circ}$, cervical sagittal vertebral axis (SVA) was $26.9 \mathrm{~mm}$, and the T-1 slope was $33.2^{\circ}$. Cervical segmental lordosis significantly increased by $6.31^{\circ}$ at 6 weeks and $6.45^{\circ}$ at 1 year. C2-7 lordosis significantly improved by 1 year with a mean improvement of $3.46^{\circ}$. There was a significant positive correlation between the improvement in segmental lordosis and overall cervical lordosis. Overall cervical lordosis was significantly negatively correlated with cervical SVA. Improved segmental lordosis was not correlated with cervical SVA in ACDF1 patients but was significantly negatively correlated in ACDF2 patients. There was also a significant positive correlation between the T-1 slope and cervical SVA.

CONCLUSIONS In the study population, the improvement of focal lordosis was significantly correlated with an improvement in overall lordosis (C1-7 and C2-7), and overall lordosis as measured by the C2-7 Cobb angle was significantly negatively correlated with cervical SVA. Using lordotic cervical allografts, we successfully created and maintained significant improvement in cervical segmental lordosis at the 6-week and 1-year time points with values of $6.31^{\circ}$ and $6.45^{\circ}$, respectively. ACDF is able to achieve statistically significant improvement in C2-7 cervical lordosis by the 1-year followup, with a mean improvement of $3.46^{\circ}$. Increasing the number of levels operated on resulted in improved cervical sagittal parameters. This establishes a baseline for further examination into the ability of multilevel ACDF to achieve cervical deformity correction through the intervertebral correction of lordosis.

http://thejns.org/doi/abs/10.3171/2016.2.SPINE151056

KEY WORDS cervical deformity; cervical kyphosis; anterior cervical discectomy and fusion; cervical lordosis; sagittal vertical axis

A NTERIOR cervical discectomy and fusion (ACDF) is a procedure that is commonly performed for focal anterior compression of the nerves roots or spinal cord, and it is also useful for correcting cervical deformity, especially in cases of focal kyphosis. ${ }^{10}$ Lor- dotic cervical cages are also widely used. Cervical lordotic grafts, although widely accepted, have been shown in a single randomized controlled trial to be equivalent to nonlordotic grafts in terms of producing cervical lordosis following ACDF. ${ }^{14}$ Another study that measured

ABBREVIATIONS ACDF = anterior cervical discectomy and fusion; $A C D F 1=1$-level ACDF; $A C D F 2=2$-level ACDF; $C l=$ confidence interval; $\mathrm{NDI}=$ neck disability index; NRS = numeric rating scale; $P O D=$ postoperative day; $S V A=$ sagittal vertebral axis.

SUBMITTED September 6, 2015. ACCEPTED February 22, 2016.

INCLUDE WHEN CITING Published online May 6, 2016; DOI: 10.3171/2016.2.SPINE151056. 
radiographic parameters after 1- to 4-level ACDF with nonlordotic allografts failed to show any statistically significant difference between the preoperative and 2-year postoperative radiographic measurements of segmental lordosis or overall cervical lordosis in 101 patients. ${ }^{3}$ Despite widespread use, the impact of lordotic allografts on radiographic alignment after 1-level ACDF (ACDF1) and 2-level ACDF (ACDF2) has not been fully examined.

The current understanding of cervical lordosis and the correction of cervical deformity continues to evolve. Kyphosis is the most common cervical spinal deformity encountered, and its correction results in improved clinical outcomes. ${ }^{9}$ Postoperative malalignment and kyphosis are associated with the development of adjacent segment disease. ${ }^{8,9}$ Tang et al. have shown that increasing cervical sagittal vertebral axis (SVA) is associated with a decreased health-related quality of life. ${ }^{9,11,12}$ By global spine assessments, the recent literature has expanded the understanding of thoracolumbar deformity and related cervical sagittal parameters to those important for thoracolumbar deformity. ${ }^{1,7}$ The ability to create and maintain cervical lordosis is an important step in optimizing overall cervical alignment and thus increasing the probability of obtaining excellent short- and long-term outcomes. Due to the increasing recognition of cervical sagittal alignment as an important indicator of cervical deformity, osteotomy techniques have been developed to gain lordosis and thereby improve cervical sagittal alignment; however, these lowercervical and upper-thoracic 3-column osteotomies can result in significant complication rates. ${ }^{9,13}$ It would be best if each and every ACDF procedure was performed in such a manner to minimize the likelihood that significant deformity will occur with time. Achieving this goal will decrease the need, in the future, for complex, expensive, and dangerous procedures in those patients who initially require only 1- or 2-level cervical fusions.

Our hypothesis is that machined cervical lordotic allografts are able to maintain or increase cervical segmental and overall lordosis. We also hypothesize that the maintenance or improvement in lordosis will have a positive impact on overall cervical sagittal alignment. This hypothesis will be tested by examining the pre- and postoperative radiographic parameters of 1- and 2-level cases (ACDF1 and ACDF2 groups, respectively).

\section{Methods \\ Patient Selection}

Seventy-four cases of ACDF1 and ACDF2 (40 ACDF1 and 34 ACDF2 patients) that were performed by the senior author (V.C.T.) were retrospectively reviewed. Preoperative upright neutral radiographs, postoperative upright neutral radiographs, and 1-year postoperative upright neutral radiographs were assessed by the first author (C.C.G.). The measured radiographic parameters included: focal lordosis, which was defined as the Cobb angle from the rostral endplate of the superior vertebral body to the caudal endplate of the inferior vertebral body of the treated segment(s); disc height, which was measured as the average of the anterior and posterior disc heights as described by $\mathrm{Li}$ et al. and Lee et al. ${ }^{5,6}$ (the height from the superior to inferior endplate of the involved vertebral body was additionally used as a measure of height and found to correlate with the averaging method for anterior and posterior disc height); $\mathrm{C} 2-7$ lordosis, as measured as the Cobb angle from the inferior endplate of $\mathrm{C}-2$ to the inferior endplate of $\mathrm{C}-7 ; \mathrm{C} 1-7$ lordosis, as measured as the Cobb angle from a horizontal line passing from the rostral-caudal midpoint of the anterior to the posterior ring of $\mathrm{C}-1$ to the inferior endplate of C-7; T-1 slope (i.e., T-1 sagittal angle), as measured as the angle of the superior endplate of T-1 compared with a horizontal line; and the $\mathrm{C} 2-7$ plumbline sagittal vertical axis (i.e., C2-7 SVA) (see Figs. 1 and 2 for examples of measured radiographs). All radiographic measurements were carried out by the first author, who is a fellowship-trained spine surgeon but did not participate in these surgeries.

Patient-reported outcome measures included the neck disability index (NDI) and numeric rating scale (NRS) for neck and arm pain. The minimal clinical improvement in each outcome measure was examined, with values based on previously reported thresholds of 7.5 for NDI and 2.5 for neck and arm NRS.,16

Statistics were calculated using Stata (version 13, StataCorp. 2013). The paired t-test was used to evaluate repeated time point measurements. Correlations between values were calculated using linear regression in order to provide a correlation coefficient.

\section{Surgical Technique}

All patients were operated on by the senior author (V.C.T.) utilizing the same surgical technique. After a standard transverse incision, sharp dissection was performed to access the anterior cervical spine. Monopolar cautery was used to dissect the longus colli muscle bilaterally and expose the lateral vertebral body to the level of the uncovertebral joints on each side. Lateral fluoroscopy confirmed the proper operative level(s), and the Thompson Spine Frame (Thompson Surgical Instruments) was used to maintain the exposure. The majority of the disc and cartilaginous endplates are removed using angled curettes and rongeurs. If there was an overhanging lip of the superior vertebral body, this was removed with a Kerrison rongeur. Cylindrical routing drill bits of sizes 5 to $7 \mathrm{~mm}$ were used to widen the interspace parallel to the endplates to create bleeding bone on these surfaces, while being careful to preserve enough endplate to minimize subsidence.

Interspace distracters were employed, as opposed to screws, within the vertebral bodies to optimize visualization, stabilize the segment, and open the foramina while the decompression was being performed. This is particularly important at the C4-5 level, which was always treated first in the ACDF2 patients. Decompression was performed using the operating microscope in every case. A high-speed bur was used to carefully resect the posterior osteophytes. Care was taken to keep the endplates straight and parallel, except for undercutting the vertebral body close to the thecal sac which may be necessary for adequate decompression. Using a small angled curette, the osteophytes over the foramina are resected and an opening through the posterior longitudinal ligament was created. One- and 2-mm Kerrison rongeurs were used 

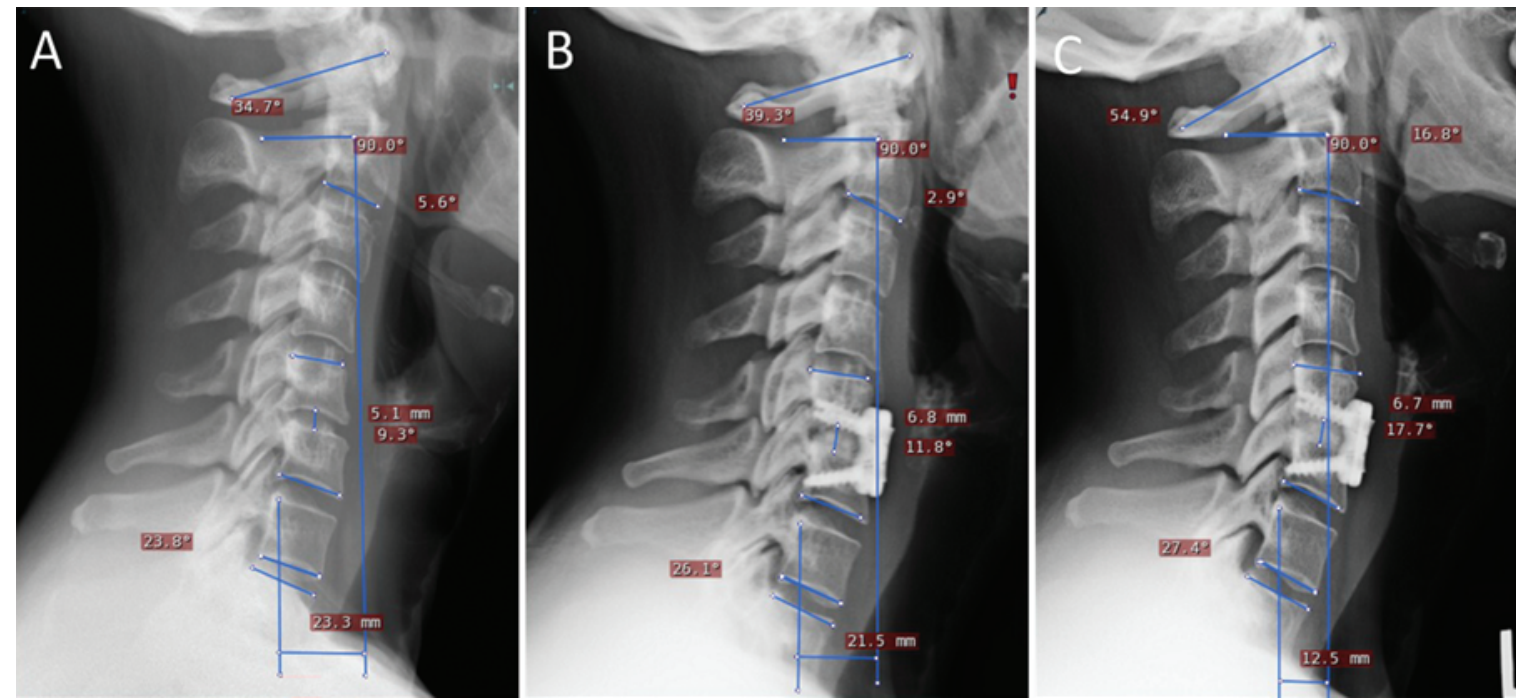

FIG. 1. Lateral neutral radiographs of a representative ACDF1 preoperatively (A), 6 weeks postoperatively (B), and 1 year postoperatively $(\mathbf{C})$. In this example, there are improvements in all sagittal and lordotic parameters at 6 weeks, which are further improved at 1 year. The correction of overall lordosis immediately improved from $-5.6^{\circ}$ (kyphosis) to $2.9^{\circ}$ at 6 weeks and then greatly improved to $16.8^{\circ}$ at 1 year. In this patient, we can see a slight improvement in SVA from $23.3 \mathrm{~mm}$ to $21.5 \mathrm{~mm}$ at 6 weeks, and again this greatly improved to $12.5 \mathrm{~mm}$ by 1 year. Figure is available in color online only.

to complete posterior longitudinal ligament removal and decompression. The decompression extended laterally to visualize both nerve roots.

Trial interbody spacers were employed and, in most cases, a graft that was $1 \mathrm{~mm}$ taller in height than the size of the routing bit used was placed. Corticocancellous al- lograft spacers with $6^{\circ}$ lordosis (Cornerstone cervical machined allograft; Medtronic) were used in every case. An appropriately sized plate was then selected, and bicortical screws were placed into the vertebral bodies using careful fluoroscopic guidance. Anterior osteophytes were drilled to ensure a tight plate fit, and 4 patients in this series had
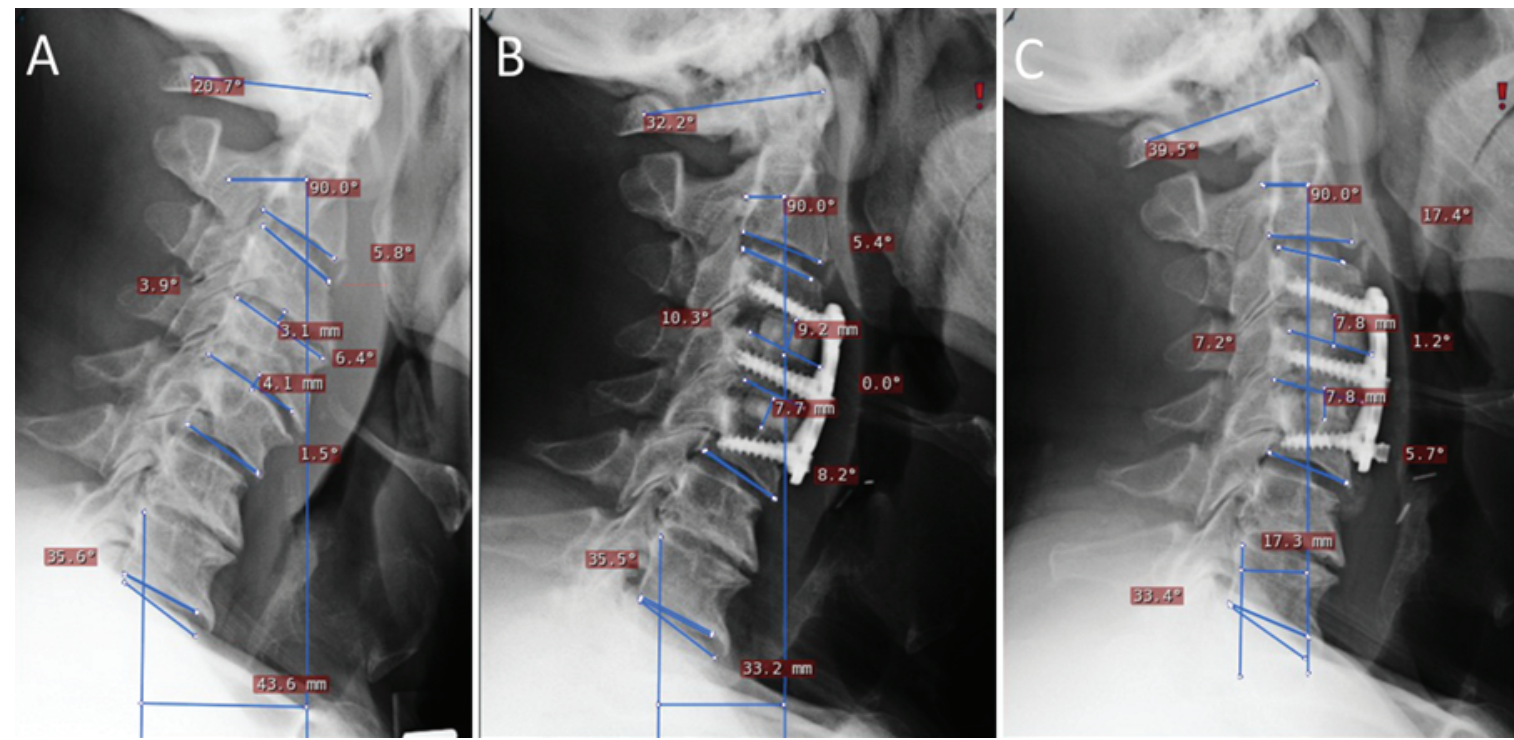

FIG. 2. Lateral neutral radiographs in a representative ACDF2 at preoperation (A), 6 weeks postoperatively (B), and 1 year postoperatively $(\mathbf{C})$. In this example, there are improvements in all sagittal and lordotic parameters at 6 weeks, which are further improved at 1 year. There is focal kyphosis at the operated segment, which is measured as $-3.9^{\circ}$ for both levels combined, and this improved to $10.3^{\circ}$ at 6 weeks and then slightly decreased to $7.2^{\circ}$ by 1 year. The correction of overall lordosis immediately improved from $-5.8^{\circ}$ (kyphosis) to $5.4^{\circ}$ at 6 weeks and then greatly improved to $17.4^{\circ}$ at 1 year. In this patient, we can see a slight improvement in SVA from $43.6 \mathrm{~mm}$ to $33.2 \mathrm{~mm}$ at 6 weeks, and again this is greatly improved to $17.3 \mathrm{~mm}$ by 1 year. Figure is available in color online only. 
minor plate bending to fit the focal angle of the disc space. A Hemovac drain was usually placed, unless the exposure was exceptionally hemostatic. The incision was closed in layers with a subcuticular suture at the skin.

\section{Results \\ Demographics}

The average patient age was 52.0 years (range 22-78 years). There were 37 male and 37 female patients. The average body mass index of the patients was 27.1 (26.8 for ACDF1 and 27.6 for ACDF2 patients). The average length of stay was 1.73 days overall: 1.55 days for ACDF1 and 2.0 days for ACDF2 patients. The most common primary diagnosis was cervical spondylosis with stenosis causing myelopathy in 52 patients (23 ACDF1 and 29 ACDF2 patients), followed by disc herniation and radiculopathy in 20 patients (17 ACDF1 and $3 \mathrm{ACDF} 2$ patients), and there was 1 case of degenerative disc disease with focal kyphosis and myelopathy in 1 ACDF2 patient. The most common levels that were operated on were 1 level at C5-6 (22 patients) and 2 levels at C5-7 (15 patients). The mean estimated blood loss was $84 \mathrm{ml}$ in total: $81 \mathrm{ml}$ in ACDF1 and $90 \mathrm{ml}$ in ACDF2 patients. The mean operative time was 124.5 minutes: 107.0 minutes for ACDF1 and 147.8 minutes for ACDF2 patients.

Medical comorbidities were recorded in 6 patients: 1 case of Type 2 diabetes in ACDF1 and 2 cases of Type 2 diabetes in ACDF2 patients; and 2 cases of multiple sclerosis in ACDF1 and 1 case of multiple sclerosis in ACDF2 patients.

There were no recognized intraoperative complications in this population. The most common postoperative complication was urinary retention requiring straight catheterization in 11 patients ( 3 ACDF1 and 7 ACDF2 patients): 10 cases resolved without additional intervention, and 1 ACDF2 patient had a urinary tract infection that was resolved with antibiotics. Dysphagia that was still present at the first follow-up occurred in 5 patients $(2 \mathrm{ACDF} 1$ and 3 ACDF2 patients), but all cases resolved by the 3-month follow-up. There were postoperative respiratory issues in 3 patients (1 ACDF1 and 2 ACDF2 patients): 2 ACDF2 patients remained intubated postoperatively for airway edema, of which 1 patient was extubated on postoperative Day (POD) 1 and 1 patient was extubated on POD 2; and in the ACDF1 group there was 1 case of prolonged intubation for edema, but the patient was extubated on POD 1. Postoperative chest pain was present in 2 patients (1 ACDF1 and 1 ACDF2 patient), but neither patient underwent electrocardiography, had troponin changes, or was diagnosed with myocardial infarction, and both were managed with observation. There was 1 case of hematoma with tracheal deviation on POD 1 that required reoperation in the ACDF2 group. Wound washout was required for a suspected infection in $1 \mathrm{ACDF} 2$ patient at 1 week postoperatively. This gives an overall rate of any postoperative complication of $31 \%$ (17.5\% in ACDF1 and $44 \%$ in the ACDF2 group).

Eight patients ( 2 patients in ACDF1 [5\% reoperation rate] and 6 patients in the ACDF2 group [17.6\% reoperation rate]) had additional surgery following $\mathrm{ACDF}$ at an average of 15.2 months after the first operation. In ACDF1, there was a plate removal for migraines (14 months postoperatively) and an adjacent segment fusion (37 months postoperatively). In ACDF2, there was the previously described hematoma removal and infection washout, and additionally there were 2 posterior fusions for nonunion (at 16 and 20 months postoperatively, respectively) and 2 procedures for adjacent segment disease (at 12 and 22 months postoperatively, respectively).

There were 3 nonunions based on either flexion/extension radiography and/or $\mathrm{CT}$ in the ACDF1 patients at 1 year (7.5\% nonunion and 93\% fusion rate at 1 year): 1 of these patients experienced 2-year follow-up imaging, giving a 95\% fusion rate at 2 years $(5 \%$ nonunion rate at 2 years), and both of the other patients were treated as asymptomatic nonunion. In the ACDF2 group, there were 6 cases of nonunion at 1 year (17.6\% nonunion and $82.4 \%$ fusion rate at 1 year). Of these patients, 5 had fusion at 1 level and nonunion at the second level. Two patients went on to have additional posterior surgery for their nonunions. The 4 conservatively treated patients remained asymptomatic. One of the conservatively treated patients went on to have fusion at the 2-year follow-up time point; however, given the number of repeat surgeries in this population, an assessment of pseudarthrosis at the 2-year time point is not possible.

Overall, the rates of complications were higher in the ACDF2 group than in the ACDF1 group. No complication or demographic variable was associated with a difference in the radiographic measurements.

Overall, the patient-reported outcome measures were available in 32 patients (17 ACDF1 patients [42.5\%] and 15 ACDF2 patients [44.1\%]) (Table 1). The mean preoperative NDI was 18.3 (21.5 for ACDF1 and 13.7 for ACDF2 patients), and the mean postoperative NDI was 11.2 (15.2 for $\mathrm{ACDF} 1$ and 10.5 for $\mathrm{ACDF} 2$ patients), giving a mean difference of -4.9 ( -6.2 for ACDF1 and -3.2 for ACDF2 patients). The minimum clinical improvement determination for NDI was reached in 7 ACDF1 patients and 4 ACDF2 patients, for NRS-neck it was reached in 9 ACDF1 patients and 6 ACDF2 patients, and for NRS-arm it was reached in $8 \mathrm{ACDF} 1$ patients and $3 \mathrm{ACDF} 2$ patients.

The only factor associated with the postoperative NDI was adjacent-segment disease (mean difference in NDI of +9 compared with -5.73 for non-adjacent segment disease

TABLE 1. Patient-reported outcome measures

\begin{tabular}{lrrcc}
\hline Measure & Preop & 1-Yr Postop & Average Change & MCID (\%) \\
\hline ACDF1 $(n=17)$ & & & & \\
\hline NDI & 21.5 & 15.2 & -6.2 & 41 \\
\hline NRS-neck & 6.1 & 2.9 & -3.1 & 53 \\
\hline NRS-arm & 4.4 & 1.2 & -3.3 & 47 \\
\hline ACDF2 $(n=15)$ & & & & \\
\hline NDI & 13.7 & 10.5 & -3.2 & 27 \\
\hline NRS-neck & 4.1 & 1.7 & -2.3 & 40 \\
\hline NRS-arm & 1.9 & 1.2 & -0.7 & 20 \\
\hline
\end{tabular}

$\mathrm{MCID}=$ minimal clinical improvement determination . 
patients; $\mathrm{p}=0.015)$. There was no association between nonunion and NDI.

\section{Radiography}

The overall preoperative mean segmental lordosis was $0.574^{\circ}$, the mean preoperative disc height was $4.48 \mathrm{~mm}$, mean $\mathrm{C} 2-7$ lordosis was $9.66^{\circ}$, mean $\mathrm{C} 1-7$ lordosis was $42.5^{\circ}$, mean cervical SVA was $26.9 \mathrm{~mm}$, and the mean T-1 slope was $33.2^{\circ}$. Segmental lordosis improved to $6.88^{\circ}$ at 6 weeks postoperatively and improved further to $7.02^{\circ}$ at 1 year, giving a mean improvement of $6.31^{\circ}\left(95 \% \mathrm{CI} 4.22^{\circ}\right.$ $\left.-7.74^{\circ} ; \mathrm{p}<0.0001\right)$ at 6 weeks and $6.45^{\circ}$ at 1 year $(95 \% \mathrm{CI}$ $\left.5.20^{\circ}-7.69^{\circ} ; \mathrm{p}<0.0001\right)$; the difference between 6 weeks and 1 year was not statistically significant. Disc height improved to $8.71 \mathrm{~mm}$ at 6 weeks and slightly decreased to $7.96 \mathrm{~mm}$ by 1 year, resulting in mean improvements of $4.22 \mathrm{~mm}$ at 6 weeks $(95 \%$ CI $3.88-4.56 \mathrm{~mm}$; $\mathrm{p}<0.0001)$ and $3.48 \mathrm{~mm}$ at 1 year $(95 \%$ CI $3.10-3.85$; p < 0.0001$)$. The difference between 6 weeks and 1 year was statistically significant (95\% CI $0.49-1.08 \mathrm{~mm} ; \mathrm{p}<0.0001)$. C2-7 lordosis improved to $12.0^{\circ}$ at 6 weeks and $13.1^{\circ}$ at 1 year, giving mean improvements of $2.34^{\circ}$ at 6 weeks $(95 \% \mathrm{CI}$ $-0.28^{\circ}$ to $4.45^{\circ} ; \mathrm{p}=0.0835$ ) and $3.46^{\circ}$ (95\% CI 1.55-5.39; $\mathrm{p}=0.0006$ ) at 1 year. $\mathrm{C} 1-7$ lordosis was similar to $\mathrm{C} 2-7$ lordosis, improving to $45.3^{\circ}$ at 6 weeks and $46.5^{\circ}$ at 1 year, giving a mean improvement of $2.80^{\circ}$ at 6 weeks $(95 \% \mathrm{CI}$ $-0.21^{\circ}$ to $5.53^{\circ} ; \mathrm{p}=0.0685$ ) and improving to $4.00^{\circ}$ by 1 year $\left(95 \%\right.$ CI $\left.1.82^{\circ}-6.19^{\circ} ; \mathrm{p}=0.0005\right)$. Cervical SVA worsened at 6 weeks to $28.1 \mathrm{~mm}$ and then improved by 1 year to $26.7 \mathrm{~mm}$, resulting in a mean worsening of 1.20 $\mathrm{mm}$ at 6 weeks (95\% CI -1.73 to $3.86 \mathrm{~mm} ; \mathrm{p}=0.4504)$ and a mean improvement of $-0.13 \mathrm{~mm}$ by 1 year $(95 \% \mathrm{CI}$ -2.45 to $2.22 \mathrm{~mm} ; \mathrm{p}=0.9156$ ). The $\mathrm{T}-1$ slope increased to $34.8^{\circ}$ at 6 weeks and, following the trend of SVA, then decreased to $34.3^{\circ}$ by 1 year, resulting in a mean increase of $1.60^{\circ}$ at 6 weeks $\left(95 \%\right.$ CI $\left.0.028^{\circ}-3.49^{\circ} ; \mathrm{p}=0.0465\right)$ and a smaller increase of $1.10^{\circ}$ at 1 year $\left(95 \% \mathrm{CI}-0.71^{\circ}\right.$ to $2.77^{\circ} ; \mathrm{p}=0.2409$ )

Looking at the 40 patients in the ACDF1 group, the mean preoperative measurements were focal lordosis of $1.36^{\circ}$, disc height of $4.47 \mathrm{~mm}, \mathrm{C} 2-7$ lordosis of $11.8^{\circ}, \mathrm{C} 1-7$ lordosis of $43.2^{\circ}$, cervical SVA of $28.9 \mathrm{~mm}$, and T-1 slope of $34.9^{\circ}$ (see Fig. 1). At 6 weeks, focal lordosis was $5.2^{\circ}$ and this improved to $5.7^{\circ}$ by 1 year, giving a mean change in focal lordosis of $3.92^{\circ}$ at 6 weeks (95\% CI 2.28-5.56; $\mathrm{p}<0.0001)$ and then $4.3^{\circ}$ by 1 year $(95 \%$ CI $2.75-5.94$; $\mathrm{p}<0.0001$ ). Disc height was measured as $8.42 \mathrm{~mm}$ at 6 weeks and $7.72 \mathrm{~mm}$ at 1 year, resulting in a mean height improvement of $3.95 \mathrm{~mm}$ at 6 weeks (95\% CI 3.23-4.66; $\mathrm{p}<0.0001$ ), which decreased by $0.697 \mathrm{~mm}$ to $3.25 \mathrm{~mm}$ at 1 year (95\% CI 2.51-3.99; p < 0.0001); this decrease of $0.697 \mathrm{~mm}$ was also significant $(95 \%$ CI $0.267-1.13$; p $=0.0022$ ). Examining the overall cervical lordosis, C2-7 lordosis improved to $13.2^{\circ}$ at 6 weeks and $15.6^{\circ}$ at 1 year, giving a mean improvement of $1.40^{\circ}$ at 6 weeks $(95 \% \mathrm{CI}$ -1.44 to $4.18 ; \mathrm{p}=0.3322$ ), which improved to a correction of $3.80^{\circ}$ at 1 year (95\% CI 1.12-6.45; $\mathrm{p}=0.0066$,). $\mathrm{C} 1-7$ lordosis improved to $45.7^{\circ}$ at 6 weeks and $48.4^{\circ}$ at 1 year, resulting in mean improvements of $2.53^{\circ}$ at 6 weeks $(95 \%$ CI -1.17 to $6.11 ; \mathrm{p}=0.178)$ and $5.21^{\circ}$ at 1 year $(95 \% \mathrm{CI}$ $\left.1.79^{\circ}-8.61^{\circ} ; \mathrm{p}=0.0038\right)$. C2-7 SVA worsened to $29.2 \mathrm{~mm}$ at 6 weeks and improved to $27.9 \mathrm{~mm}$ by 1 year, giving a mean worsening of $0.05 \mathrm{~mm}$ at 6 weeks $(95 \% \mathrm{CI}-6.33$ to $6.42 \mathrm{~mm} ; \mathrm{p}=0.988)$ and improvement of $-0.95 \mathrm{~mm}$ by 1 year ( $95 \% \mathrm{CI}-8.35$ to $5.28 \mathrm{~mm}$; $\mathrm{p}=0.651)$. The $\mathrm{T}-1$ slope was essentially the same at 6 weeks postoperatively at $35.0^{\circ}$ and again at 1 year with a value of $35.2^{\circ}$, resulting in minimal mean change of $0.080^{\circ}$ at 6 weeks $(95 \%$ $\mathrm{CI}-1.75$ to $1.90 ; \mathrm{p}=0.932$ ) and $0.280^{\circ}$ at the 1 -year time point (95\% CI -2.45 to $3.08 ; \mathrm{p}=0.818$ ).

The ACDF2 patients had an overall mean preoperative (both levels combined) focal kyphosis of $-0.329^{\circ}$, the overall mean disc height was $4.49 \mathrm{~mm}, \mathrm{C} 2-7$ lordosis was $7.15^{\circ}$, mean $\mathrm{C} 1-7$ lordosis was $41.7^{\circ}$, mean cervical SVA was $24.6 \mathrm{~mm}$, and the mean T-1 slope was $31.3^{\circ}$ (see Fig. 2). Focal lordosis was $8.77^{\circ}$ at 6 weeks and $8.53^{\circ}$ at 1 year, resulting in a mean increase of $9.10^{\circ}\left(95 \%\right.$ CI $5.19^{\circ}-11.6^{\circ}$; $\mathrm{p}<0.0001)$ at 6 weeks which was maintained with a mean change from baseline of $8.86^{\circ}$ at 1 year $\left(95 \%\right.$ CI $7.19^{\circ}$ $\left.10.5^{\circ} ; \mathrm{p}<0.0001\right)$. The disc height improved to $8.89 \mathrm{~mm}$ at 6 months and $8.09 \mathrm{~mm}$ at 1 year, resulting in mean changes of $4.38 \mathrm{~mm}$ at 6 weeks (95\% CI 3.95-4.82 mm; p < 0.0001 ) and losing $0.836 \mathrm{~mm}$, thereby resulting in a mean decreased change of $3.61 \mathrm{~mm}$ at 1 year (95\% CI 3.14-4.07 $\mathrm{mm} ; \mathrm{p}<0.0001$ ); the decrease between 6 weeks and 1 year was also significant $(95 \% \mathrm{CI}-0.429$ to -1.24 ; $\mathrm{p}<0.0001)$. For overall cervical lordosis, $\mathrm{C} 2-7$ lordosis was $10.5^{\circ}$ at 6 weeks and decreased slightly to $10.2^{\circ}$ by 1 year, resulting in a mean change of $3.34^{\circ}$ at 6 weeks $\left(95 \% \mathrm{CI}-1.18^{\circ}\right.$ to $\left.7.05^{\circ} ; \mathrm{p}=0.155\right)$ and a loss of $0.3^{\circ}$ and a mean change of $3.11^{\circ}$ at 1 year $\left(95 \%\right.$ CI $\left.0.193^{\circ}-6.205^{\circ} ; \mathrm{p}=0.0374\right)$. C $1-7$ lordosis was $44.8^{\circ}$ at 6 weeks and again decreased slightly to $44.3^{\circ}$ at 1 year, resulting in a mean improvement of $3.10^{\circ}$ at 6 weeks $\left(95 \% \mathrm{CI}-1.88^{\circ}\right.$ to $\left.7.64^{\circ} ; \mathrm{p}=0.2260\right)$ and decreasing by $0.470^{\circ}$ to a mean change of $2.63^{\circ}$ at 1 year $\left(95 \% \mathrm{CI}-0.062^{\circ}\right.$ to $\left.5.33^{\circ} ; \mathrm{p}=0.0552\right)$. Cervical SVA was measured at $26.8 \mathrm{~mm}$ at 6 weeks postoperatively and improved to $25.4 \mathrm{~mm}$ at 1 year, resulting in a mean increase of $2.18 \mathrm{~mm}$ at 6 weeks $(95 \% \mathrm{CI}-2.67$ to $7.04 \mathrm{~mm}$; $\mathrm{p}=$ 0.367 ), and, with the effect lessened, an increase of 0.794 $\mathrm{mm}$ at 1 year $(95 \% \mathrm{CI}-2.65$ to $4.24 \mathrm{~mm} ; \mathrm{p}=0.642)$. The T-1 slope increased to $34.5^{\circ}$ at the 6 -week postoperative time point and decreased down to $33.2^{\circ}$ by 1 year, giving mean changes of $3.75^{\circ}$ at 6 weeks $\left(95 \%\right.$ CI $0.670^{\circ}-6.83^{\circ} ; \mathrm{p}$ $=0.0186)$ and $1.85^{\circ}$ at 1 year $\left(95 \% \mathrm{CI}-0.253^{\circ}\right.$ to $3.96^{\circ} ; \mathrm{p}$ $=0.0826)$. A summary of the mean changes in the radiographic parameters can be found in Table 2 .

Through calculation of the sample correlation coefficient, we identified a significant relationship between the change in the value of $\mathrm{C} 1-7$ lordosis and $\mathrm{C} 2-7$ lordosis as a control value (6 weeks: $r=0.770, p<0.00001 ; 1$ year: $\mathrm{r}=0.719, \mathrm{p}<0.00001)$. The change in $\mathrm{C} 2-7$ lordosis was more highly correlated with cervical SVA than C1-7 lordosis (C2-7 at 6 weeks: $\mathrm{r}=-0.338, \mathrm{p}=0.00374 ; \mathrm{C} 2-7$ at 1 year: $\mathrm{r}=-0.311, \mathrm{p}=0.00794 ; \mathrm{C} 1-7$ at 6 weeks $\mathrm{r}=$ $-0.204, p=0.0836 ; C 2-7$ at 1 year: $r=-0.128, p=0.281$ ) (see Fig. 3). We further examined other relationships and found significant positive correlations between the change in the T-1 slope and cervical SVA (6 weeks: $\mathrm{r}=0.368, \mathrm{p}=$ 0.00138 ; 1 year: $r=0.484, p<0.00001$ ) and focal lordosis and the change in $\mathrm{C} 2-7$ lordosis ( 6 weeks: $\mathrm{r}=0.500$, $\mathrm{p}<$ 0.0001; 1 year: $r=0.249, p=0.0335$ ) (see Fig. 4). Looking 
TABLE 2. Radiographic measurements in the ACDF1 and ACDF2 groups and the overall mean change at 6 weeks and 1 year postoperatively

\begin{tabular}{|c|c|c|c|c|c|c|}
\hline Timepoint & $\begin{array}{c}\text { Focal Lordosis } \\
\left({ }^{\circ}\right)\end{array}$ & $\begin{array}{l}\text { Disc Height, } \\
\mathrm{mm}\end{array}$ & $\begin{array}{c}\text { C2-7 Lordosis } \\
\left({ }^{\circ}\right)\end{array}$ & $\begin{array}{c}\text { C1-7 Lordosis } \\
\left({ }^{\circ}\right)\end{array}$ & $\begin{array}{c}\text { C2-7 SVA, } \\
\mathrm{mm}\end{array}$ & $\begin{array}{c}\text { T-1 slope } \\
\left({ }^{\circ}\right)\end{array}$ \\
\hline \multicolumn{7}{|l|}{ ACDF1 $(n=40)$} \\
\hline Preop & 1.36 & 4.47 & 11.8 & 43.2 & 28.9 & 34.9 \\
\hline 6 wks postop & 5.28 & 8.42 & 13.2 & 45.7 & 29.2 & 35.0 \\
\hline Mean change from preop to 6 wks postop & 3.92 & 3.95 & 1.36 & 2.47 & 0.050 & 0.080 \\
\hline 1 yr postop & 5.71 & 7.72 & 15.6 & 48.4 & 27.9 & 35.2 \\
\hline Mean change from preop to $1 \mathrm{yr}$ & 4.34 & 3.25 & 3.78 & 5.20 & -0.95 & 0.280 \\
\hline Mean change from 6 wks to $1 \mathrm{yr}$ & 0.43 & -0.70 & 2.40 & 2.70 & -1.3 & 0.20 \\
\hline \multicolumn{7}{|l|}{ ACDF2 $(n=34)$} \\
\hline Preop & -0.329 & 4.49 & 7.15 & 41.7 & 24.6 & 31.3 \\
\hline 6 wks postop & 8.77 & 8.89 & 10.5 & 44.8 & 26.8 & 34.5 \\
\hline Mean change from preop to 6 wks postop & 9.10 & 4.38 & 3.34 & 3.10 & 2.18 & 3.75 \\
\hline $1 \mathrm{yr}$ postop & 8.53 & 8.09 & 10.2 & 44.3 & 25.4 & 33.2 \\
\hline Mean change from preop to $1 \mathrm{yr}$ & 8.86 & 3.61 & 3.11 & 2.60 & 0.794 & 1.85 \\
\hline Mean change from 6 wks to $1 \mathrm{yr}$ & -0.24 & -0.83 & -0.30 & -0.50 & -1.40 & -1.30 \\
\hline \multicolumn{7}{|l|}{ Overall $(n=74)$} \\
\hline Preop & 0.574 & 4.48 & 9.66 & 42.5 & 26.9 & 33.2 \\
\hline 6 wks postop & 6.88 & 8.71 & 12.0 & 45.3 & 28.1 & 34.8 \\
\hline Mean change from preop to 6 wks postop & 6.31 & 4.23 & 2.34 & 2.80 & 1.20 & 1.60 \\
\hline 1 yr postop & 7.02 & 7.96 & 13.1 & 46.5 & 26.7 & 34.3 \\
\hline Mean change from preop to $1 \mathrm{yr}$ postop & 6.45 & 3.48 & 3.46 & 4.00 & -0.20 & 1.10 \\
\hline Mean change from 6 wks to $1 \mathrm{yr}$ & 0.14 & -0.75 & 1.11 & 1.20 & -1.4 & -0.5 \\
\hline
\end{tabular}

at the overall data, the segmental change in lordosis was significantly correlated with cervical SVA at 6 weeks $(\mathrm{r}=$ $-0.274 ; p<0.05)$, but not at 1 year $(r=-0.165 ; p=0.166)$. In the ACDF1 group, the change in lordosis was not significantly correlated with the change in cervical SVA at 6 weeks $(r=-0.204 ; p=0.0836)$ or 1 year $(r=-0.176 ; p=$ 0.290 ), but in the ACDF2 group the change in lordosis was significantly correlated with the change in cervical SVA at both 6 weeks $(r=-0.39 ; p=0.0267)$ and even more so at 1 year $(r=-0.41 ; p=0.00105)$ (see Fig. 5$)$.

\section{Discussion}

Villavicencio et al..$^{14}$ performed a radiographic analysis in 85 patients, in which $68(80 \%)$ patients maintained or improved their segmental lordosis and $17(20 \%)$ patients had decreased segmental lordosis (i.e., became more kyphotic postoperatively) with an average loss of $3^{\circ}$. Their patients were divided into lordotic and parallel-graft groups and had an average of $1^{\circ}$ and $2^{\circ}$ of focal lordosis preoperatively and $16^{\circ}$ and $17^{\circ}$ of overall cervical lordosis preoperatively. The study population included 1- to 3-level ACDFs, and these investigators employed measurements based on posterior vertebral body tangential lines instead of Cobb angles. Their mean postoperative segmental lordosis was measured as $6^{\circ}$ and $7^{\circ}$ and the mean postoperative overall cervical lordosis was $18^{\circ}$ and $19^{\circ}$, giving a mean improvement of $2^{\circ}$ in cervical sagittal alignment and $5^{\circ}$ in focal lordosis. These values were not presented with any subdivision by the number of levels performed. In comparison, our population had greater improvement in focal segmental lordosis with $4.3^{\circ}$ at 1 year in the ACDF1 group, $8.9^{\circ}$ in the ACDF2 group, and an overall mean of $6.4^{\circ}$. Our overall cervical C2-7 lordosis-which is the closest measure to Villavicencio et al.'s cervical sagittal alignment value (i.e., overall cervical lordosis) - changed by $3.8^{\circ}$ at 1 year in the ACDF1 group and $3.1^{\circ}$ in the ACDF2 group; again, this is greater than that reported by Villavicencio et al.'s group. The measurement differences between these studies could be related to the use of Cobb angles in our study compared with the tangential lines used by Villavicencio, although we are most interested in comparing the change in values rather than the absolute values. Additionally, the discrepancy could result from differences in the proportion of 2-level patients who were measured (and who had greater lordotic correction), but the relative proportion of 2- and 3-level patients in the analysis by Villavicencio et al. were not described. Their inclusion of 3-level patients, however, would have presumably resulted in even greater focal correction. The reasoning for this smaller improvement in C2-7 lordosis seen in our ACDF2 patients is likely related to the greater burden of degenerative disease and the presence of worse preoperative kyphosis.

$\mathrm{Wu}$ et al ${ }^{15}$ examined radiographic parameters postoperatively and at the final follow-up in 46 patients who underwent 1-level ACDF and 11 patients who underwent 2-level ACDF using stand-alone titanium cages. $\mathrm{Wu}$ et al. found a mean change in $\mathrm{C} 2-7$ lordosis of $2.5^{\circ}$ postoperatively and $3.2^{\circ}$ at the last follow-up; these values 


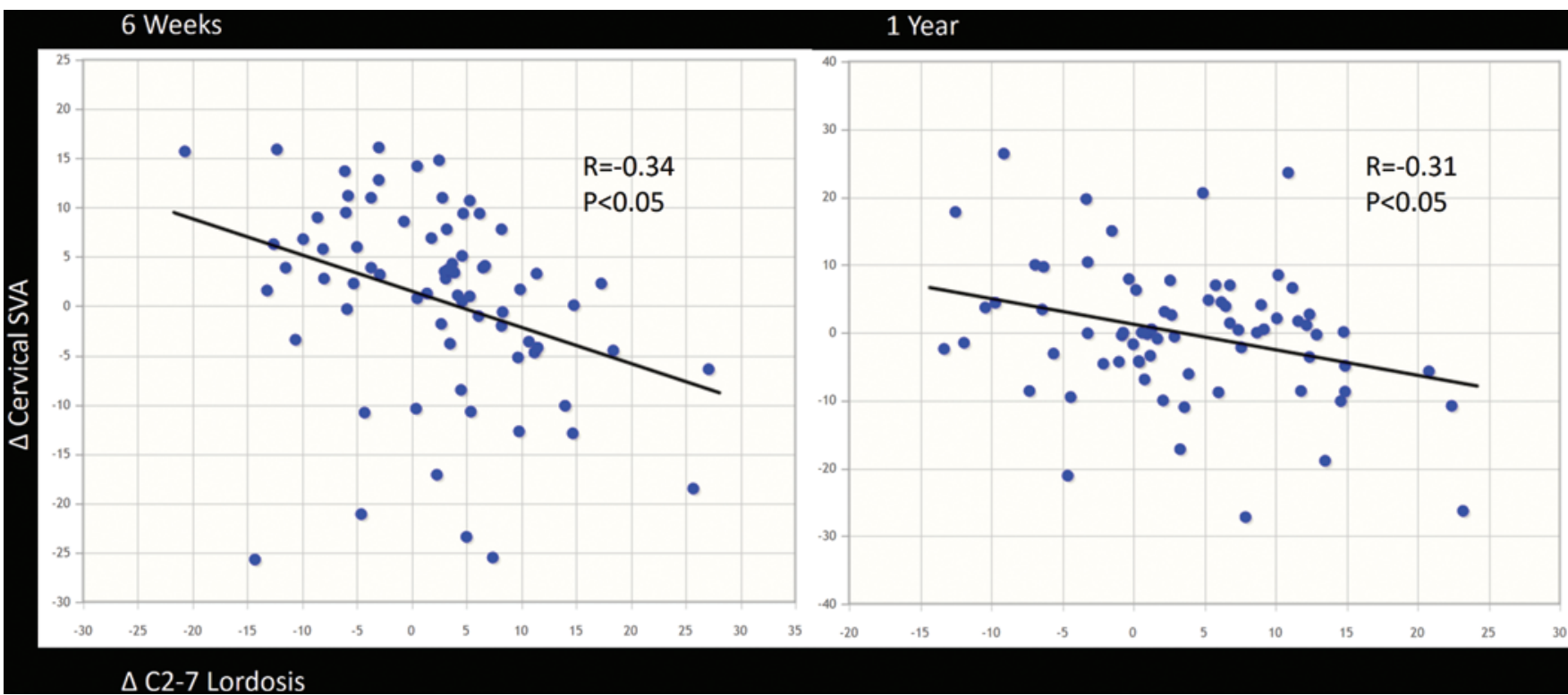

FIG. 3. Graph of the mean change in cervical SVA compared with the mean change in overall C2-7 cervical lordosis. A scatterplot is shown with the superimposed calculation of the correlation coefficient and the resultant regression line, both at the 6 -week and 1 -year time points. This regression analysis shows a statistically significant $(p<0.05)$ negative correlation $(R=-0.34 ; R=-0.31)$ between the change in $\mathrm{C} 2-7$ lordosis and cervical SVA both at 6 weeks and 1 year. Figure is available in color online only.

were very similar to our overall 6-week $\left(2.34^{\circ}\right)$ and 1-year $\left(3.46^{\circ}\right)$ values. The segmental lordosis in Wu et al.'s series improved by a mean of $3.6^{\circ}$ postoperatively and $1.2^{\circ}$ at the last follow-up; these values were, again, less than those achieved in our study $\left(6.3^{\circ}\right.$ at 6 weeks and $6.4^{\circ}$ at 1 year). The reasons for the difference in segmental lordosis are likely related to the use of nonlordotic grafts, and again this could be related to the proportion of ACDF2 patients included (only $20 \%$ in Wu et al.'s study) and the fact that the results were not subdivided by the number of levels that were operated on.

Comparing our study to Wu et al.'s study in light of the findings of Villavicencio et al., it appears that the use of lordotic versus nonlordotic grafts does not have an effect

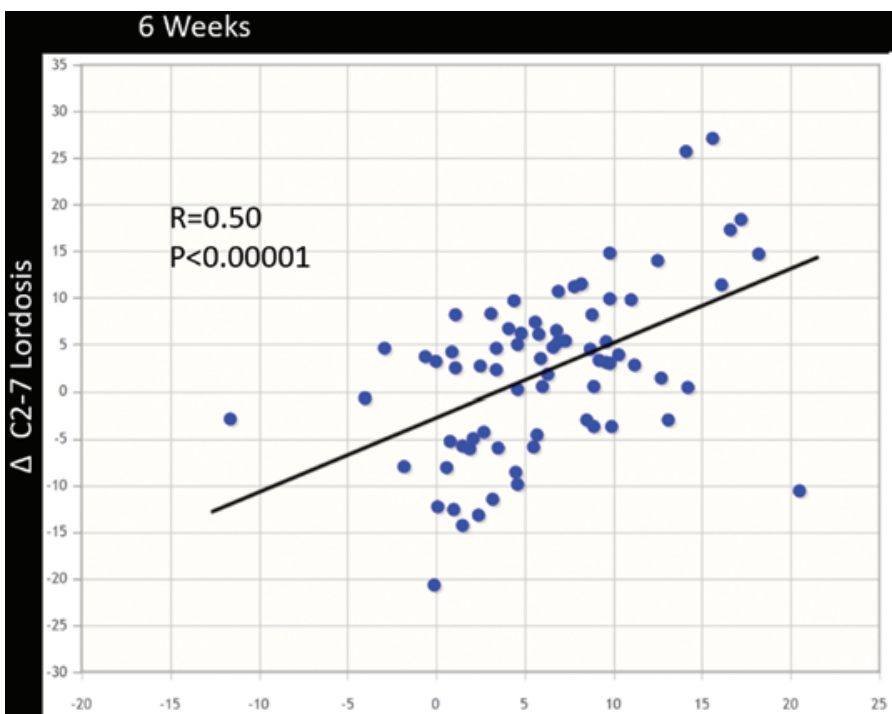

1 Year

\section{$\Delta$ Focal Lordosis}

FIG. 4. Graph of the mean change in overall cervical lordosis (measured from C-2 to C-7) compared with the mean change in focal lordosis. A scatterplot is shown with the superimposed calculation of the correlation coefficient and the resultant regression line, both at the 6 -week and 1 -year time points. The regression analysis shows a statistically significant $(p<0.05)$ positive correlation $(R=0.5$ and $R=0.24$, respectively) between the change in focal lordosis and the overall lordosis. This relationship is stronger at the 6 week than the 1-year time point, based on $\mathrm{R}$ and $\mathrm{p}$ values. Figure is available in color online only. 


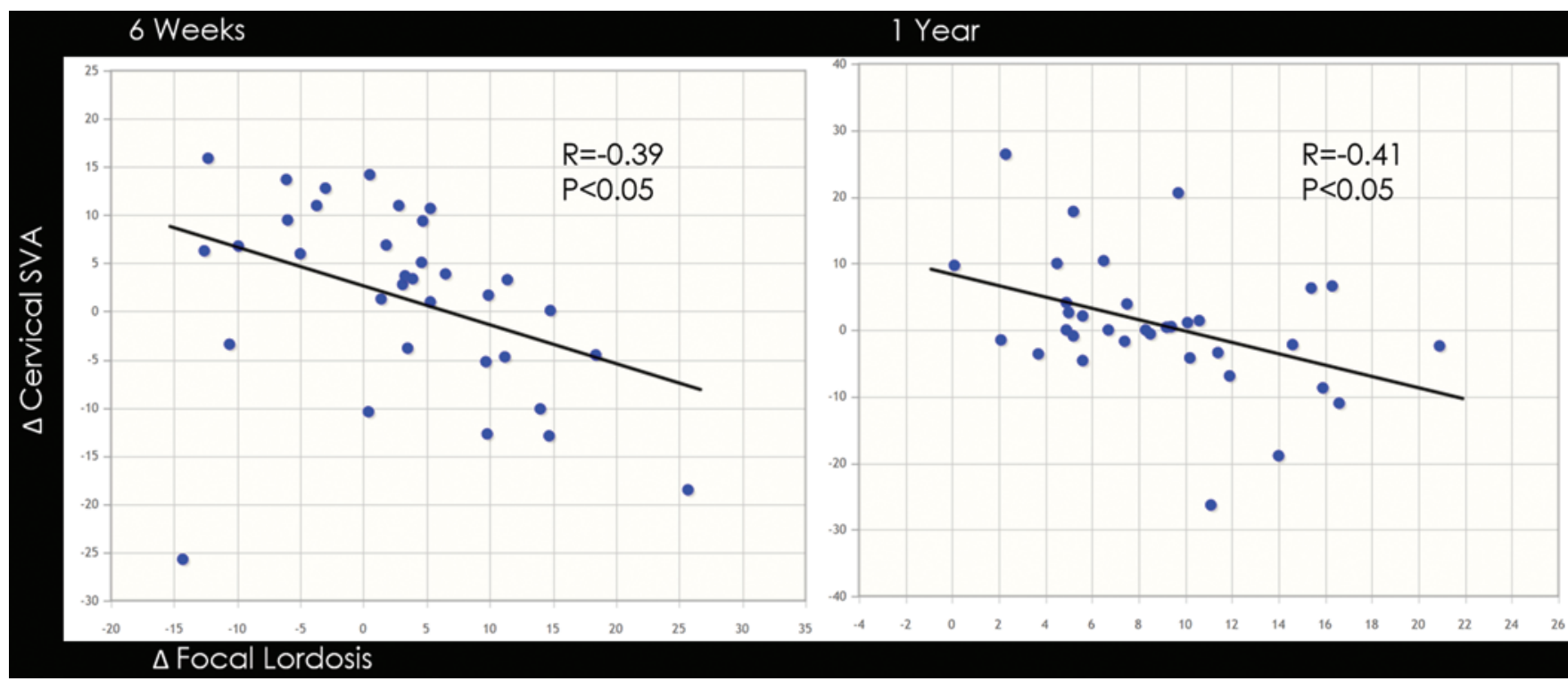

FIG. 5. Graph of the mean change in cervical SVA compared with the mean change in focal lordosis in ACDF2. A scatterplot is shown with the superimposed calculation of the correlation coefficient and the resultant regression line, both at the 6-week and 1 -year time points. This regression analysis shows a statistically significant $(p<0.05)$ negative correlation $(R=-0.39$ and $R=$ -0.41 , respectively) between the change in focal lordosis and cervical SVA in ACDF2 at both 6 weeks and 1 year. Figure is available in color online only.

on overall cervical lordosis after ACDF, but possibly does have an effect on the ability to achieve improved segmental lordosis. We can additionally note that Villavicencio et al.'s, Wu et al.'s, and our study are all in agreement regarding the ability of ACDF to improve radiological parameters after ACDF and are in contrast to the findings of Gum et al., who found no significant difference in the 2-year radiographic parameters compared with the preoperative values despite the inclusion of 1- to 4-level ACDF patients. ${ }^{3}$

Looking at the correlation between the change in cervical segmental lordosis, the change in overall cervical lordosis, and cervical SVA, we found a significant positive correlation between the change in segmental lordosis and the change in overall cervical lordosis (C2-7 or C1-7). This is in agreement with Villavicencio et al., who found that a change in focal lordosis was a predictor of change in overall cervical lordosis. ${ }^{14}$ The T-1 slope was also found to be significantly positively correlated with cervical SVA. The finding of the T-1 slope correlating with cervical SVA is consistent with the results of Knott et al., ${ }^{4}$ who found a moderately strong correlation between these 2 variables (Spearman $r=0.65$ ), although our correlation coefficient was weaker $(r=0.48)$. We did, however, find a greater correlation between cervical lordosis and cervical segmental lordosis with cervical SVA. The change in C2-7 lordosis was significantly negatively correlated with the change in cervical SVA: the increase in C2-7 lordosis correlated with the decrease in cervical SVA. In the overall population, we did not find a significant correlation between the change in segmental lordosis and cervical SVA at 1 year; however, this relationship was significant when looking at the ACDF2 group, and the relationship strengthened by the 1-year time point, showing that an increase in segmen- tal lordosis was correlated with a decrease in the cervical SVA at 6 weeks, and this was further improved by 1 year. Given that this relationship was not significant in the ACDF1 group and became significant in the ACDF2 group suggests that the addition of further levels of intervertebral correction would also be correlated with a further improvement in cervical SVA.

The interesting observation of worsening cervical SVA at 6 weeks prior to stabilization or improvement by 1 year may be related to postoperative muscle spasm and pain. Another possibility is that rotationally dynamic screws were used in all constructs. Additionally, we observed that this particular relationship extended to the change in T-1 slope, which has been described as a surrogate measure of overall cervical sagittal balance itself $f^{4}$ and, in concordance with the literature, was significantly correlated with cervical SVA in our data set.

Patient outcome measures were not available in a majority of our patients. The NDI and NRS-neck and -arm scores improved on average in all patients, and having adjacent segment disease was statistically associated with a worsening of NDI. Due to the percentage of patients in which these scores were available, it is difficult to make any determinations from this information.

A limitation of this paper is that it represents a singlesurgeon series with a single technique that encompasses many of the characteristics of the standard ACDF technique, and the conclusions of this paper should take this into account. The data show what is possible with this ACDF technique.

\section{Conclusions}

Lordotic cervical allografts are able to successfully 
create and maintain significant improvement in cervical segmental lordosis at the 6 -week and 1-year time points, with values of $6.31^{\circ}$ and $6.45^{\circ}$, respectively. ACDF is able to achieve statistically significant improvement in $\mathrm{C} 2-7$ cervical lordosis by the 1-year follow-up with a mean improvement of $3.46^{\circ}$. Increasing the number of levels of intervertebral correction allows for a greater ability to improve focal lordosis. This is especially pronounced when coupled with the knowledge that the ACDF2 patients started with greater preoperative focal deformity and focal kyphosis.

In our population, the improvement in focal lordosis was significantly correlated with an improvement in overall lordosis (C1-7 and $\mathrm{C} 2-7$ ), and overall lordosis as measured by the $\mathrm{C} 2-7 \mathrm{Cobb}$ angle was significantly negatively correlated with cervical SVA. In the ACDF2 group, the correction of segmental lordosis was significantly correlated with an improvement in cervical SVA, and this relationship was strengthened from 6 weeks postoperatively to 1 year postoperatively, suggesting that 6-week cervical SVA is not as reliable as 1-year cervical SVA for observing the amount of sagittal correction achieved. This establishes a baseline for further examination of the ability of multilevel ACDF to achieve cervical deformity correction through the intervertebral correction of lordosis.

\section{References}

1. Ames CP, Blondel B, Scheer JK, Schwab FJ, Le Huec JC, Massicotte EM, et al: Cervical radiographical alignment: comprehensive assessment techniques and potential importance in cervical myelopathy. Spine (Phila Pa 1976) 38 (22 Suppl 1):S149-S160, 2013

2. Carreon LY, Glassman SD, Campbell MJ, Anderson PA: Neck Disability Index, Short Form-36 physical component summary, and pain scales for neck and arm pain: the minimum clinically important difference and substantial clinical benefit after cervical spine fusion. Spine J 10:469-474, 2010

3. Gum JL, Glassman SD, Douglas LR, Carreon LY: Correlation between cervical spine sagittal alignment and clinical outcome after anterior cervical discectomy and fusion. Am J Orthop 41:E81-E84, 2012

4. Knott PT, Mardjetko SM, Techy F: The use of the T1 sagittal angle in predicting overall sagittal balance of the spine. Spine J 10:994-998, 2010

5. Lee YS, Kim YB, Park SW: Risk factors for postoperative subsidence of single-level anterior cervical discectomy and fusion: the significance of the preoperative cervical alignment. Spine (Phila Pa 1976) 39:1280-1287, 2014

6. Li J, Li Y, Kong F, Zhang D, Zhang Y, Shen Y: Adjacent segment degeneration after single-level anterior cervical decompression and fusion: disc space distraction and its impact on clinical outcomes. J Clin Neurosci 22:566-569, 2015

7. Oh T, Scheer JK, Eastlack R, Smith JS, Lafage V, Protopsaltis TS, et al: Cervical compensatory alignment changes following correction of adult thoracic deformity: a multicenter experience in 57 patients with a 2-year follow-up. $\mathbf{J}$ Neurosurg Spine 22:658-665, 2015
8. Park MS, Kelly MP, Lee DH, Min WK, Rahman RK, Riew KD: Sagittal alignment as a predictor of clinical adjacent segment pathology requiring surgery after anterior cervical arthrodesis. Spine J 14:1228-1234, 2014

9. Scheer JK, Tang JA, Smith JS, Acosta FL Jr, Protopsaltis TS, Blondel B, et al: Cervical spine alignment, sagittal deformity, and clinical implications: a review. J Neurosurg Spine 19:141-159, 2013

10. Shriver MF, Lewis DJ, Kshettry VR, Rosenbaum BP, Benzel EC, Mroz TE: Pseudoarthrosis rates in anterior cervical discectomy and fusion: a meta-analysis. Spine J 15:2016-2027, 2015

11. Tang JA, Scheer JK, Smith JS, Deviren V, Bess S, Hart RA, et al: The impact of standing regional cervical sagittal alignment on outcomes in posterior cervical fusion surgery. Neurosurgery 76 (Suppl 1):S14-S21, 2015

12. Tang JA, Scheer JK, Smith JS, Deviren V, Bess S, Hart RA, et al: The impact of standing regional cervical sagittal alignment on outcomes in posterior cervical fusion surgery. Neurosurgery 71:662-669, 2012

13. Theologis AA, Tabaraee E, Funao H, Smith JS, Burch S, Tay $\mathrm{B}$, et al: Three-column osteotomies of the lower cervical and upper thoracic spine: comparison of early outcomes, radiographic parameters, and peri-operative complications in 48 patients. Eur Spine J 24 (Suppl 1):S23-S30, 2015

14. Villavicencio AT, Babuska JM, Ashton A, Busch E, Roeca C, Nelson EL, et al: Prospective, randomized, double-blind clinical study evaluating the correlation of clinical outcomes and cervical sagittal alignment. Neurosurgery 68:1309-1316, 2011

15. Wu WJ, Jiang LS, Liang Y, Dai LY: Cage subsidence does not, but cervical lordosis improvement does affect the longterm results of anterior cervical fusion with stand-alone cage for degenerative cervical disc disease: a retrospective study. Eur Spine J 21:1374-1382, 2012

16. Young BA, Walker MJ, Strunce JB, Boyles RE, Whitman JM, Childs JD: Responsiveness of the Neck Disability Index in patients with mechanical neck disorders. Spine J 9:802808,2009

\section{Disclosures}

Dr. Traynelis states that he is a consultant for Medtronic, holds patents with Medtronic, and receives non-study-related clinical or research support from Globus and AO.

\section{Author Contributions}

Conception and design: Gillis. Acquisition of data: Gillis, Kaszuba. Analysis and interpretation of data: all authors. Drafting the article: Gillis, Traynelis. Critically revising the article: all authors. Reviewed submitted version of manuscript: Gillis. Approved the final version of the manuscript on behalf of all authors: Gillis. Statistical analysis: Gillis. Study supervision: Traynelis.

\section{Correspondence}

Christopher C. Gillis, Division of Neurosurgery, University of Nebraska Medical Center, 982035 Nebraska Medical Center, Omaha, NE 68198-2035. email: chriscgillis@gmail.com. 